\title{
Integrating 5S Principles with Process Improvement: A Case Study
}

\author{
Kem Ramdass \\ University of South Africa, Department of Mechanical and Industrial, Johannesburg, South Africa
}

\begin{abstract}
Lean manufacturing may be applied predominantly in the manufacturing environment, however it is aptly applicable to the service industry as well. $5 \mathrm{~S}$ may be considered as a tool of lean as it reduces waste and adds value to the process. It may be combined with other tools such as Kanban, Kaizen, total preventive maintenance, total quality management in addressing pertinent issues in the workplace. Thus managers' face increased pressure to improve performance within their organisations. Performance management is the "buzzword," including national and international competition. In order to accomplish this objective with a decreasing workforce, managers are empowering employees to take responsibility on productivity and performance. By creating a workplace that is conducive to achieve this performance, in consideration of health and safety, work design and productivity, the implementation of the 5-S principles can become one of the sustainable competitive advantages in industry. The objective of the study is to highlight that many organisations, both manufacturing and service, lose millions of rands in the form of waste on a regular basis. Therefore integrating these principles into a plant's culture can cut worker's compensation costs, reduce lost time, improve productivity and quality and strengthen labour-management relations. The objective of this paper is to highlight that $5 \mathrm{~S}$ principles are fundamental to the workplace and to indicate that the monetary value of waste across the spectrum is insurmountable. In order to achieve this, a case study methodology was used as it was the most applicable method of collecting data. The best way to make the 5-S principles an integral part of plant culture is to develop a plant-wide programme. The study provides an overview of workplace challenges experienced. It is the researcher's intention to emphasize the importance of these basic principles and its associated benefits for all stakeholders through an exploratory research design.
\end{abstract}

\section{INTRODUCTION}

The future of the clothing, textile, leather and footwear industry is at stake due to national and international competition. Workplaces are based on "efficient movement of product" or best locations for machines. This is done without giving the thought to how people are supposed to fit into their workplace. Issues such as injuries, errors in production (repairs) and efficient motions are often neglected. People are expected to adapt themselves to fit into whatever arrangement has been devised, believing that it has no associated costs [12]. Space limitations are a major contributor to poor efficiencies. Crowding of the workplace with pre-cut components of garments aggravate low efficiency. Some tasks require operator training in contortionist sewing techniques which is done in the workplace. The human body cannot adapt to every situation.
People have differences and they have limitations and this issue is not evaluated thoroughly before contracting people on the job [5;27].

The industrial environment is plagued with unhygienic workplaces, health and safety hazards, waste, poor efficiency and effectiveness and demotivated personnel. This is costing the South African economy millions of rands per annum in hidden costs. The impact of these factors have caused a decline in the economic viability of many industries and thus led to closures of the organisations. In view of this, case studies were conducted at organisations to determine the current status and to determine the effects of the implementation of $5 \mathrm{~s}$ principles [7;27].

\section{METHODOLOGY}

Principally, two research methods are usually adopted, namely: the qualitative and quantitative methods. The qualitative method involves interacting with the group of people being investigated, and sometimes may even require living within the group (Cooper and Schindler). The qualitative method has limitations in its application and questions have been raised regarding its reliability. In addition, Cooper and Schindler observes that the qualitative method is time consuming and therefore, makes it impractical to apply at times, even though it may be most favoured by researchers. The quantitative method on the other hand has been deemed to be reliable and allows data collection to be across a large spectrum of organisations. In most instances, the quantitative method is achieved by collecting data through the use of questionnaires.

The current study adopted the qualitative methodology, hence a case study conducted both in the textile and clothing industries. Qualitative case study methodology provides tools for researchers to study complex phenomena within their contexts. When the approach is applied correctly, it becomes a valuable method to develop theory, evaluate situations, and develop interventions. It is a method used to narrow down a very broad field of research into one easily researchable topic. Whilst it may not answer a question completely, it will give some indications and allow further elaboration on the subject. The case study research design is also useful for testing whether scientific theories and models actually work in the real world [9]. The study was conducted through observations and discussions in both the clothing and textile industry. Literature reviews were also conducted as a theoretical underpinning of the research. 


\section{LITERATURE REVIEW}

Introduction to 5-S Principles

5-S is the acronym for five Japanese words: seiri, seiton, seiso, seiketsu and shitsuke which, when translated, means organisation, neatness, cleanliness, standardization and discipline respectively. They have been referred to as the five keys to a total quality environment. Takashi Osada developed the original concept of 5-S in the early 1980s. He coined the concept as the five principles to a total quality environment. These concepts are totally applicable to any workplace. The practice of the 5-S principles is not only useful for the workplace but also helps them personally by improving their thinking process $[1 ; 6]$. The logic behind the 5 -S principles at the workplace is that these principles are the basic requirements for high efficiency in producing better quality products and services with little or no waste. The effectiveness of 5-S is shown by its popularity in Japan where the concept has been introduced, albeit mainly in the manufacturing and service industries. The major car manufacturer, Toyota, is one of the pioneering firms to adopt the 5-S principles.Seiri, seiton, seiso, seiketsu and shitsuke are the five Japanese words which are collectively called the 5-S principles. 5-S proponents refer to it as a step-by-step approach towards achieving a total quality environment [8;17]. The meaning of the $5-\mathrm{S}$ as follows:

\section{A. First $S$ - seiri (organisation/sort)}

A key concept in organisation is stratification management. Translated simply, it means classifying all items and data so that they can be properly treated. Being able to classify an item would enable decisions to be made about the importance of the item, to decide what to discard and what to save, and to keep the number of things and quantity of each item that are necessary as low as possible so as to reduce the non-essential inventory. The necessary data should then be entered into the database; the necessary items stored at a convenient location, permitting easy access when required later. Stratification management thus separates things that are necessary for the job from those that are not, and ensures that essential things are close at hand for easy retrieval, resulting in maximum efficiency.

To support stratification management, it is important to be able to identify each item, giving it a name that is easily recognisable by all. A proper name should be assigned to everything to prevent confusion as some items may have a real name but people often refer to them using a common name.

Another concept under organisation is the principle of "one is best" - practices of one-day processing, one-hour meetings, one-page reports, one-location storage, one-method processes. This simplicity reduces confusion and increases efficiency in work processes $[11 ; 18 ; 19]$.

\section{B. Second $S$ - seiton (set in place/neatness)}

"A place for everything and everything in its place, "the second step, is a storage principle in which everything in the work area has a place and is always stored there when not in use. Neatness focuses on the layout and structure of the office and workplace. It involves where and how the necessary items are placed. Obstructions to work flow will be easily identified and removed by having a clearly defined layout. Decisions must be made whether the storage locations should be centralised or decentralised. Such decisions would be based on the usage frequency and function of the items. In general, items and tools stored must be placed where they are needed, easily noticed, accessible, in the order required for utilisation, and not in obstruction of work processes [2;16].

Safe storage should also be practised, like storing heavy items at the bottom. For ease and safety, there must be provision of proper ladders or chairs for retrieval of items stored at higher levels. Other than storage, attention must also be paid to the other aspects of workplace layout. The position and height of the tools and equipment should enable the worker to maintain good posture for his comfort while making process movements.For proper storage, decisions regarding the necessary items as identified under organisation have to be made as to where each necessary item should go, and how it is to be stored and retrieved. If possible, the item's name should also be labelled at the storage location to ensure proper storage. Markers and labels can be used for this purpose $[2 ; 17 ; 18]$.

There is a need for a proper system of identification, labelling, and work process flows that everyone can understand, follow and maintain. Special attention must be paid to the tidiness of notices and signs, as these are common means of communication and also project an image of how a company is. Proper places should be designated for the placement of the signs. These should be placed neatly at a convenient height so that they can be seen and yet not be an obstruction. There should also be an indication of how long the notices should be up and they should be taken down when they are no longer required. This will keep them up to date and people will be constantly aware of new notices. The notices should also be of a proper size, and neatly typed with a clear heading $[2 ; 19]$.

\section{Third S - seiso (cleanliness)}

The third step is 'shine' or scrub to keep the work place clean by eliminating all forms of dirt, dust, grease and grime. Cleanliness of the area is visible to everyone. To maintain a good image of cleanliness, everyone should be individually responsible for cleaning. Areas should be charted out; responsibility for cleaning assigned to personnel, leaving no areas undefined or unaccounted for. Throwing out things that are unnecessary will uncover areas for inspections. Discarding unwanted items will make the area clear and uncluttered. Obsolete data must be removed so that they will not create confusion. Visibility is effective in tackling problems as it may uncover the cause of problems and thus 
enable one to deal with the root of the problems. This makes it possible to pre-empt problems and thus prevent their reoccurrence. Daily inspection, lubrication and cleaning of equipment are part of preventive maintenance that will increase efficiency of the machinery. Cleaning must thus be done daily and inspections can be incorporated to ensure that this is done religiously. Cleaning should be extended even to areas not usually obvious, such as the washroom $[6 ; 20]$.

\section{Fourth $S$ - seiketsu (standardisation)}

The fourth step, 'standardize,' is where working conditions are implemented to maintain sort, set in place, and shine. Standardization creates a consistent way that tasks and procedures are carried out so that absolutely anyone can understand the work. "Seeing is believing"; thus emphasis must be placed on visual management. Standardised conditions on site must be achieved so that work can be done quickly. Standardisation also creates transparency, where everyone is clear of procedures, knows exactly where things are and how things are done; thus there are no hidden areas. A better understanding of what one's colleague is doing enables one to work better. It also allows the work processes to continue in the event of an employee being absent for the day. Employees are also better able to point out ways to improve operations if they can understand the company's operations as a whole. In addition, following standardised procedures makes it easy to see which inventories are out of stock and which are missing. This helps in the organisation of the office $[2 ; 23]$.

Colour management can be used to create a more visually pleasing working environment. Standardised visual aids like indicators, labels and markers are easily recognisable and make communication simple and understandable, so that everyone can act quickly.

\section{E. Fifth $S$ - shitsuke (discipline to sustain)}

The fifth step is 'sustain,' which endeavours to develop a culture of following the correct procedures and continuously repeating all the steps of the $5 \mathrm{~s}$ process. By sustaining all of the $5 \mathrm{~s}$ steps, many problems in the work place can be avoided. It is important to mention that organisations fail to embed the values of sustaining or maintaining the implementation and thus revert to "square one" $[3 ; 4 ; 24]$.

Commitment from all stakeholders is imperative in order to gain the rewards of this programme. Moreover, the rewards may be seen over a period of time and difficult to quantify. However, one of the case studies would demonstrate the saving gained on the reduction of waste in the textile industry $[20 ; 23]$.

Discipline means instilling the ability to do things the way they are supposed to be done. This involves training and inculcating good habits and having everyone practise them, thus encouraging the continuity of good habits. As the final $\mathrm{S}$ in the 5-S, it propagates the 5-S practice by ensuring that the former 4-Ss are carried out conscientiously. Making the 5-S a daily routine helps to maintain orderliness at the workplace.
Setting up the 5-S is useless if it is not followed through, as things will return to being bad if they are not well maintained. Taking a further step, discipline also includes reviewing current practices and revising them to keep them relevant. It also means striving for kaizen, which is the Japanese equivalent for continuous improvement [21].

The application of these new technologies is having a profound social impact, not only upon the total numbers and location of those employed in clothing manufacture, but also upon the skills, training and management needs of organisations. Almost all industrial manufacturing facilities use some type of work or labour standards to measure productivity and forecast costs. Traditionally this has been the domain of industrial engineers or work-study officers, who analyse the situation and use various methods to arrive at a standard time. Proper work standards are often a necessary part of ensuring the economic efficiency of a manufacturing company. Jobs with high-energy expenditure and whole-body fatigue are the primary cause of increased costs and loss of productivity $[4 ; 10]$.

Ramdass points out that studies conducted in the 1970s and 1980s by ergonomists Marvin Dainoff, Michael Brill, Stephen Margulis, Tim Springer and others, focused on workstations and indicated a definite relationship between worker performance and working conditions. They found that the problems with most workstations centred on two designrelated problems - the physical components of the workstation and the nature of the job or job design [18].

Contributing to the comfort factor are anthropometrics issues. Today's workforce is multiracial, male and female, and includes disabled and ageing workers. Body shapes, sizes, capabilities and limitations vary greatly, yet many workstations do not take these factors into consideration, as they are set up in a rigid structure. To compound these problems, workplace physical structures may be designed for a minority of workers [13;23].

A "good" workstation, (one that promotes machineworker interface) therefore, should be developed with the anthropometric measurements of the majority of workers as a standard and should allow flexibility. In addition to these physical layout problems, the pace of work and the type of work have changed. Employees are expected to produce more output quickly, and, because of the faster access to information, employees are being asked to make more and more decisions around their tasks. These factors are potential stress builders [3;14].

Organisations are feeling the inefficiencies and loss of productivity due to poor application of $5 \mathrm{~S}$ principles. Workplaces should be designed to be human friendly as employees spend approximately one third of their lives at the workplace. A sound understanding of workplace dynamics and the work activity being studied is necessary [9].

Peng [26] mentioned the significance of implementing a competitive strategy that would enhance manufacturing capabilities in order to compete in the global economy. A competitive strategy would cultivate strengths that could be 
2015 Proceedings of PICMET '15: Management of the Technology Age

TABLE 1. DIFFERENCES BETWEEN OSADA'S AND HIRANO'S APPROACHES (ADAPTED FROM HIRANO 1996; OSADA 1991).

\begin{tabular}{|l|l|l|}
\hline 5S & Takashi Osada & \\
\hline Seiri & $\begin{array}{l}\text { Organisation : To organize things in order for ease of use and } \\
\text { removing unnecessary items }\end{array}$ & Organisation: Eliminate unneeded items \\
\hline Seiton & $\begin{array}{l}\text { Neatness: Everything in its place, a place for everything. } \\
\text { Eliminate searching }\end{array}$ & Orderliness: Enable easy retrieval. \\
\hline Seiso & Cleaning: Create a faultless environment through cleaniness & Cleanliness: Keep everything clean and neat. \\
\hline Seiketsu & $\begin{array}{l}\text { Standardisation: continuous improvement through organization, } \\
\text { neatness and cleaning }\end{array}$ & $\begin{array}{l}\text { Standardised clean up: Make the 5s part of the culture of the } \\
\text { organisation }\end{array}$ \\
\hline Shitsuke & $\begin{array}{l}\text { Training or discipline: Imbibe the principles of 5s through } \\
\text { continuous training and development. }\end{array}$ & Discipline: Form a habit through procedures. \\
\hline
\end{tabular}

used as a weapon against competing organisations.

The dimensions of competition vary in its context and have been argued extensively. Organisations implement priorities according to their needs. Ward et al [30] identified five different dimensions namely price; quality; dependability; product flexibility; and volume flexibility.

Glock and Kunz [15] argued that organisations should use criteria that win the orders. He focussed on price, delivery, quality, product design and variety. Hill also mentioned performance as qualifying criteria in an organisations quest for service delivery.

Krajewski and Ritzman [22] mentioned "a more detailed list by differentiating four different aspects namely, cost; quality; time; and flexibility. Their list then included low-cost operations, high-performance design, consistent quality, fast delivery time, on-time delivery, development speed, customisation, and volume flexibility."

Stevenson [29] mentioned that an organisation can compete on three major issues namely:

- cost leadership - competing on the basis of price;

- differentiation - a unique product that is valued by customers; and

- focus - a niche market for its products developed on cost and differentiation strategy.

Through the development and continuous training of people, the $5 \mathrm{~S}$ principles can become part of the organizational culture [25].

\section{DISCUSSION AND RESULTS}

A. Company A - textile manufacturing focus on waste management

Company A is an international thread producer and starts the production process with spinning, twisting, dyeing, lubrication and final winding. The organisation began focussing on process improvement through the employment of a work-study officer. The function was related to the application of work-study principles for performance measurement and management. The company implemented "house-keeping" as a means of ensuring a clean and healthy work environment. The company agreed that $5 \mathrm{~s}$ was the right tool to start with in order to clean up and promote cooperation among the workers in the area.

The work-study officer observed that tons of waste being produced and a person hired to cut up the waste from the spindles. An analysis of the waste was done per department.

An average of 152789.00 South African Rands were lost per annum on waste of materials in the production process. As part of the project of implementing 5s principles, the work-study officer decided to provide costs in the various stages of the production process. The loss due to waste production was provided in a detailed report to the executive management and highlighted to each departmental manager.

The next step was an investigation into the causes of waste in each department. The following report summarises the causes of waste.

TABLE 2: BREAKDOWN OF WASTE AND COSTS PER DEPARTMENT

\begin{tabular}{|c|c|c|c|c|}
\hline & SPINNING & TWISTING & DYEING & FINISHING \\
\hline JANUARY & $57(16.50)$ & $125(18.00)$ & $300(25.00)$ & $85(33.00)$ \\
\hline FEBRUARY & 128 & 400 & 235 & 56 \\
\hline MARCH & 255 & 350 & 255 & 86 \\
\hline APRIL & 85 & 352 & 145 & 120 \\
\hline MAY & 120 & 285 & 186 & 95 \\
\hline JUNE & 95 & 125 & 85 & 51 \\
\hline JULY & 112 & 156 & 128 & 123 \\
\hline AUGUST & 100 & 115 & 201 & 76 \\
\hline SEPTEMBER & 68 & 125 & 98 & 102 \\
\hline OCTOBER & 125 & 300 & 129 & 84 \\
\hline NOVEMBER & 80 & 250 & 158 & 100 \\
\hline DECEMBER & 138 & 96 & 100 & 63 \\
\hline & $1363(22489)$ & $2523(45414)$ & $2020(50500)$ & $1042(34386)$ \\
\hline
\end{tabular}


2015 Proceedings of PICMET '15: Management of the Technology Age

TABLE 3. BREAKDOWN OF CAUSES OF WASTE
\begin{tabular}{|l|l|l|l|}
\hline SPINNING & TWISTING & DYEING & FINISHING \\
\hline No filament & Incorrect twist & Incorrect colour & Operator error \\
\hline No cotton & Wrong ply & Machine malfunction & Machine error \\
\hline Defective material & Defective machine & Operator error & Quality standards not met \\
\hline Defective rollers & Quality standards not met & Quality standards not met & \\
\hline Worn rollers & Variance in spindle turns & Defective input material & \\
\hline Defective input material & Operator error & & \\
\hline Quality standards not met & & & \\
\hline
\end{tabular}

A programme was developed to address the above problems. Regular discussion on the $5 \mathrm{~s}$ principles was implemented and drastic measures were taken to reduce waste throughout the organisation. The maintenance team was asked to investigate and correct all machine related problems. Human resources performed training and retraining on all operator-related problems and the work-study department provided standard operating procedures for all operations. The quality department performed quality tests on all input/output of materials on a regular basis. Weekly productivity and operator efficiency reports, together with the waste report were presented to executive management since inception. This was carefully scrutinised and each departmental manager was asked to report on the progress that was made using the $5 \mathrm{~s}$ principles.

At the end of the $2^{\text {nd }}$ year of implementation, the entire workforce celebrated the success of the $5 \mathrm{~s}$ principles over two weeks of soccer and a braai. The organisation saved approximately $80 \%$ in waste costs over a 3 year period.

\section{RESULTS AND DISCUSSION OF 5-S IN THE CLOTHING INDUSTRY}

\section{A. Visual displays}

The clothing industry uses visual displays to communicate operator and line output per hour through a production board at the end of the line, sewing operations and stitch length information in standard operating procedure format using an A4 white board inserted into a plastic jacket, quality inspection procedures on the quality inspection table, and other relevant data and information for effective and efficient production.

\section{B. Standardization of work process}

Currently, virtually every manufacturer in SA clothing industry operates on the principle of the bundle system. The Bundle System (BS) is a system that uses bundles of cut components that are tied together in a bundle. These bundles travel from operator to operator until the garment is fully assembled. The operators' work station is specialised to handle the different types of sewing operations involved in the construction of the garment. The machinists specialise in the different operations to achieve labour efficiency. The Bundle System is as old as the clothing industry and organisations still practice this method of assembly around the world [27].
Work is passed to sewing machines in bundles of cut pieces. The number of cut parts in the bundle may vary according to weight or the complexity of operations required, but the principle remains the same: the operator unties the bundles, sews the cut parts together, re-ties the bundle, processes the work ticket and places the bundle into a bin or on a transporter system (a $U$ shaped manual conveyor).The bundle then goes to another machinist who repeats a similar sequence; a bundle may be tied and untied several times before it completes its lengthy journey.

There are a few (3) clothing organisations in the sample using the "chain system" where parts of the garment move on an overhead chain suspended on a track. This system is part of the bundle system as component parts of the bundle flow in sequence to prevent mis-match of the garment. At the end of the chain is a clip that holds pieces together. The system of production in the industry has evolved over a period of time into modular and the conveyor system. Through systematic workplace dynamics, operator fatigue reduced and operator efficiency improved by $20 \%$ [27].

\section{Quick Changeover}

Quick changeover, one of the $5 \mathrm{~s}$ principles is used in reducing waste in garment manufacturing process. When setting up a production line for a new style, there is loss of approximately 30 minutes. Through careful pre-planning , whereby mechanics and operators set up the line by moving machines as a batch of products is being completed. Through simple planned changeover, time is reduced by approximately $50 \%[27]$.

\section{Motion economy}

When the machine and attachments have been selected, it becomes necessary to develop the most efficient motion pattern for the operator. This includes how the operator brings in the work, how the pieces of garment need to be aligned, how the sewing procedure needs to take place, how the garment is disposed. This requires the principles of ergonomics [27;23;30].

The clothing machinist normally sits in one position the entire day. The hands and feet operate the machine during the sewing procedure. The layout of the components of work need to be strategically positioned to create a smooth flow and become rhythmic. Prevent reaching out for components, tools and machine operation for an extended period where fatigue can set in. 


\section{Proceedings of PICMET '15: Management of the Technology Age}

- Work surfaces should be adjustable to worker anthropometry.

- In general, work should be organized within the person reach without stretching.

- All controls of the machine should be placed within the normal working area.

- Use both hands during operation in symmetrical and opposite directions to reduce fatigue.

- Design operations so that all fingers are used to avoid overload

- Try to use gravity in the operation.

- Working in normal posture. Try not to bend parts of the body into awkward positions.

- Change posture when necessary.

- Locate all working tools in position.

\section{E. 5.5 Workload balancing}

Line balancing is the distribution of work on the line in such a way that all machinists obtain an equal amount of work in terms of time value. All workers should be productive during the day and production should flow smoothly, thereby achieving planned targets. The objective is to accurately delegate workers to the various operations required to complete the product based on their operational skills and to maximise productivity and delivery as per the planned targets [27].

One of the major oversights on the part of management is that they do not indicate the link between labour costing, order scheduling, line balancing and control to the line staff. Line balancing has 2 stages:

- Pre-planning

- Control

Both stages are inter-complementary and extremely important.

Pre-Planning: Planning includes theoretical calculations \& assumptions and is generally guided by past practical experience (and in most cases reliant on the memory of the supervisor). It takes into account operation complexities, machinery and productivity constraints.

Historically the method of allocating workers and operations was based purely on a 1 machinist to 1 operation basis. When bottlenecks were experienced, additional labour was allocated to minimise the constraint. Although this achieved the desired effect, labour utilisation was sacrificed. Thus, the productivity of the line was poor, and with lack of measurement practices, there was no factual information to address the situation. Supervisors used under-balanced workers for the preparation of the next order which was not required and thus over-stocked work in progress. The resultant effect was the production of products under stressful conditions for the workforce [2].

In order to address this situation, an operation bulletin was drawn up during the garment costing stage using predetermined motion time studies such as GSD (general sewing data) or synthesis, indicating the sequence of operations, necessary machinery and equipment. Just before production could commence the operator allocation bulletin was handed to the supervisor for the allocation of operations. Follow-up procedures were adopted to verify the operation bulletin using work-study principles. Discrepancies were ratified and kept on record for future consultation. The follow-up is often related to forceful methods of target achievement and often unfair to workers allocated to critical operations. This causes discontentment among the workforce and leads to high labour absenteeism and labour turnover, with necessary skills being lost. Where standard minute values are available, the balancing of the line becomes simple and can be completed via a simple spreadsheet exercise on a computer. This method is used by the proactive individuals who realise that one has to drive the balance rather than let it drive the individual.

Accurate worker to operation ratios were established based on time value expressed as SMV (standard time value). The results reflected that some workers were required for a full day while others were required for only a portion of the day to complete the tasks required. This entails the reliance on the number of different skills possessed by every worker and the ability of the supervisor to optimize the use of these skills which usually manifests itself in the "control" function of line balancing. Effective line balance planning and control was implemented and improved output of a production line in the region of $30 \%$ [27].

\section{DISCUSSION OF BARRIERS AND SOLUTIONS FOR IMPROVEMENT}

Common themes emerged during discussions of this research in both the textile and the clothing industries.

\section{A. Labour and management}

There was a feeling of animosity between managerial staff and the workforce. This was due to yearly strikes on wage demands, damage of property and "us and them" scenario. Working in an atmosphere like this prevents progression in the organisation. It was felt that this gap in communication needs to me mended as a matter of urgency so that all could work productively together for the common goal of the organisation [26;28].

Solution: For any organisation to prosper there needs to be a healthy work environment - "it all revolves around open communication". In discussions with senior management it was suggested that all levels of staff attend emotional intelligence workshops, management and leadership workshops, and "other workshops" as required. This education and training commitment would build relationships among all members of staff.

\section{B. 6.2 Lack of understanding}

Before any project implementation, it is crucial that discussions occur and all stakeholders understand how they 
would be affected. The lack of buy-in leads to disapproval and resistance to change [27].

Solution: Open discussions with all stakeholders with the development of a project plan on the scope, value and implications of implementation. This should include education and training, discussions and a well- structured plan of action with the monitoring of progress at all stages of the project.

\section{6.3 Management commitment}

Any change in the organisation stems from top management. Commitment from management drives the process of change and nothing can be achieved if management does not support the initiative. Once management gives their approval any change is possible, but employees need to understand and support the changes for it to be successful. Any project has to have the "blessings" of management and the acceptance from employees for it to be successful. The managing director of the organisation initiated the process of change in terms of funding. Support from management, especially in terms of funding is important for a project of this nature [16;19].

Solution: Management to commit to make resources available on projects

\section{6.4 Taking ownership and responsibility}

All employees need to take ownership of their workplace and the surrounding areas. In view of complaints about each other, and the way forward, stakeholders need to focus on the taking ownership and responsibility to accord the progression or closure of the industry. In a study concluded in 2009 by Ramdass, it was noted that the SA clothing industry shed over 67000 jobs in the past three years [7].It is estimated that 10000 jobs are shed every year.

Solution: A commitment from all stakeholders to take responsibility and ownership that would enable the organisation to reach its desired goals.

\section{E. 6.5 Machine maintenance}

Machines are not in good working order.

Solution: Develop a project plan for the maintenance and replacement of parts

The following steps are suggested to formally implement 5-S into the organisation:

\section{Step 1: Management commitment}

It is not only essential to obtain approval from top management on the implementation of the system, but for it to be well received, top management must also be committed to it. It would be ideal if the implementation programme is spearheaded by a member of the top management. Commitment should be demonstrated by allocating resources for the preparation and implementation of the programme. To further express their commitment, top management should be personally undergoing $5-\mathrm{S}$ training and practising the principles. Such a hands-on approach will be the best demonstration of their commitment. Top management must be able to accept the idea that there may be faults with the current methods of working and are receptive to advice and change to improve, and will seek to find solutions together with the employees [14].

\section{Step 2: Education}

The company should try to attend courses about 5-S. Enquiries can be made to national productivity and standards boards as these agencies could have conducted such courses before. If the company has the resources, it can invite the 5-S chairperson of companies who have implemented 5-S, or even other 5-S gurus to come to the company to give a seminar and help to structure a 5-S programme catered to the needs of the company. Should these avenues prove to be too costly, there is an increasing amount of literature regarding 5S. Self-study can be done easily as the 5-Ss are not difficult concepts to understand [21].

\section{Step 3: Train the trainer}

To prepare for the implementation of the 5-S system, it is essential to identify the people who will be put in charge of the 5-S efforts in the various departments. Decentralising the efforts can allow each effort to be more focused on the respective area. In addition, there will be greater accountability and thus a better chance of success. Having said that, coordination is still important as the whole company is working together to achieve the same goal. One department cannot excel without the support of the other departments. Standardisation across departments should be achieved wherever possible. Having appointed the people in charge, the next step would be to train them. This can be called the "Train the trainers programme". It is essential that the people in charge of the 5-Ss in the various departments be adequately trained so that they can take appropriate corrective actions where necessary. These people will then become the trainers for their department and be responsible for training the rest of the employees in that department [24].

\section{Step 4: Promotional campaign}

To assist the newly trained trainers, a company-wide promotional campaign is recommended. Ideas will be better accepted if employees know that this is a company-wide effort and they are not alone in doing it. Employees would not think that it is an additional chore that they have to take on. Each department, headed by the respective trainers, must come up with its own plan to suggest improvement methods for their own department, on top of the standard changes that must be made. Each employee must be trained to understand the 5-S concepts, to accept the idea, so as to be able to identify areas for improvement. Tapping on the principles of marketing, promotional posters can be placed up neatly at designated places to advocate $5-\mathrm{S}$ and to constantly remind everyone to practise the 5-S principles even after the promotional programme is over. This is an intensive one- 


\section{Proceedings of PICMET '15: Management of the Technology Age}

week campaign to aggressively promote the 5-S principles and encourage their practice. A schedule must be set up to schedule the activities that are to be carried out [18]. Each area of the 5-S will be focused during its designated day as follows:

- First 5-S day - organisation (e.g. throw away things you do not need).

- Second 5-S day - neatness (e.g. name everything and assign locations).

- Third 5-S day - cleanliness (e.g. all- together housecleaning).

- Fourth 5-S day - standardisation (visual management and transparency for things).

- Fifth 5-S day - discipline (e.g. do your own 5-S audit).

Step 5: evaluation of 5-S programme

To round up the promotional programme, a prize presentation should follow to reward the departments where $5-\mathrm{S}$ is best practised. This would not only encourage the winning departments to continue to practise the 5-Ss to keep up their good performance, but also serves as an incentive for other departments to improve themselves. It is not enough to cease efforts after one week of intensive 5-S practices. Evaluations should be done during the debriefing of the promotional programme, and the feedback obtained can serve as valuable inputs to plan for the sustenance of the 5-S system.

\section{Step 6: maintaining the system}

There should be 5-S inspections conducted regularly, the dates of which should, however, not be revealed. This is to avoid last minute efforts to spruce up the department to acceptable standards. The 5-S activities should be practised daily so that there should not be any anxiety during the inspections at all. The following are some ideas that can be taken up to ensure the maintenance of the system.

\section{Employee participation and generation of ideas}

The 5-S training should be incorporated into the orientation plans for new employees. This would not only ensure proper integration of the new employees but also that the good practices would continue. For self-sustaining progress, all employees should be encouraged to identify their own problems and formulate their own solutions for continuous improvement. Regular department-wide or company-wide meetings should be organised to allow avenues for people to discuss their practices and announce their results. The exchange of ideas and information is often just what is needed to keep everybody fresh [10].

As with so many other things, it is very easy to get into a routine with the 5-S activities - particularly because they demand constant everyday attention to routine details. The inspections and meetings are thus needed to keep everyone updated of what is happening and to spot problems before they develop into major complications. Feedback and suggestion channels, and brainstorm circles can even be formed as alliances with other companies who also practise the 5-S principles. Ideas can be exchanged between companies and this may even serve as a launch pad for other strategic alliances between the different companies.

\section{Cross-evaluation of departments}

In essence, to keep everyone interested, there is a need to devise ways that will get everybody competing in a friendly but no less intense manner. To encourage friendly competition, cross-evaluation exercises can be introduced to promote the exchange of ideas and learning. Each department trainer will be the auditor for another department, thus creating a counter audit arrangement for each department [8].

\section{Tools to support programme maintenance}

Other than the promotional posters to publicise the 5-Ss, other tools can be made, for example, instructional signs. The company should invest in standardised labels for use throughout the whole company. Other examples include the provision of special shelves, and more rubbish disposal tools. The 5-S audit worksheet is also an essential tool to ensure that all compliance requirements are adhered to [6].

\section{Maintaining records}

Photographs are one excellent way of keeping records. There should be both full-view pictures of the workplace and close-up pictures of specific parts and places indicating all the important phases of the 5-S implementation. These photographs provide points of reference for both the employees involved and external auditors, and can also be used to publicise the progress at company-wide 5-S meetings. Comprehensive evaluation criteria should be set up in the form of an easy-to-use checklist, which can be uniquely named as the 5-S audit worksheet. The 5-S worksheet can also be customised and adapted for suitable use in each department. The worksheet helps to ensure that all aspects have been covered, and reduces the amount of preparation time required to conduct audits. To be able to compare results between departments and over time, it would be necessary to quantify results to make them visible. Scores assigned can also be statistically analysed to reveal the results achieved and how much improvement has been accomplished. Revisions to the audit worksheet should be made as and when new ideas are generated or when there are structural changes in order to keep the system relevant.

\section{CONCLUSION}

Organisations would ask why they would need to embrace the 5-S concept and implement it since it provides no recognised certification and thus provides no publicity for the organization. The general benefits of practising the 5-S principles have already been expounded above. In addition to those benefits, the 5 -S principles provide a framework within which the ISO 9001:2000 requirements can be built on. There is another way in which the practice of the 5-S principles can 
assist in the achievement of the ISO 9001:2000 certification. In the certification process, external auditors would come to the organisation for an initial visit, when the auditor does a preliminary site walk through before the actual audits are conducted. As first impressions often make the most lasting impressions, it is important to be able to present, at the initial visit, a neat and clean work area, thus giving a good impression of a well-organised work area. In fact, dubious areas may often present a risk in the actual audits conducted later. Such good housekeeping may be achieved by practising the 5-S principles religiously. Thus, if an organization has already been practising the 5-S principles, there would not be any cause for worry when the external auditors arrive.

The 5-S principles also propose the regular maintenance as well as constant review and evaluation of implemented quality management systems. This is again a critical requirement for ISO 9001:2000 certification. An organisation is not encouraged to slacken and then to buck up just before an external or ISO 9001:2000 half-yearly audit takes place. Discipline, as proposed in the 5-S principles, ensures that the organisation carries out its own regular internal audits to ensure consistent conformity to the ISO 9001:2000 requirements. In the long run, the integration of ISO 9001:2000 requirements with 5-S principles would lead towards TQM.

For 5-S to work effectively for the company, the implementation has to involve all employees and departments in the company, and utilise all tools available. Changing the organisation's structure involves rearranging its internal systems, such as its lines of communication, work flow, or managerial hierarchy. Changing the organisation's technology means altering its equipment, engineering processes, research techniques, or production methods. Changing the organisation's people involves changing the selection, training, relationship, attitudes, or roles of organisation members $[1 ; 4 ; 6]$. Good management at all stages is important to ensure good implementation. A chain is only as strong as its weakest link. Thus the commitment of top management and each employee is crucial to successful team performance [8].

Finally, the resistance to change is one issue which organisations should pay attention to when implementing the 5-S principles. The 5-S principles have been presented as five simple words to guide and streamline operations. These may be misinterpreted as trivial, and thus an organisation might reckon it should not waste time incorporating them into its work flow. Reservations might arise when considering whether or not to embrace the 5-S principles in an organisation. For example, why clean when things will get dirty again? Valuable time should not therefore be wasted on these ideas, since the 5-Ss will not contribute towards increased output. Things will go back to being bad anyway, so why bother to clear up? To dispel such resistance, it must first be recognised that these concerns are only short-term concerns. The 5-S practices are meant to be a self-sustaining, long-term improvement programme. The benefits can only be reaped from continuous practice, which results from a disciplined workforce. The beauty of the 5-S concept being "trivial" is that it can easily be remembered and practised. Time would only have to be spent initially for the orientation and education of employees when the 5-S principles are first introduced. When properly practised, things will not get dirty, nor will they revert to being bad again. Furthermore, work conditions will be improved and efficiency increased. This will enable output to be of a higher quality, thus attracting more clients, and increasing output and profits - all of which results from effective team performance management through the Japanese 5-S principles [6].

\section{REFERENCES}

[1] Ablanedo-Rosas, J., B.; Alidaee, J. C. Moreno ; and J. Urbina. "Quality Improvement Supported by the $5 \mathrm{~S}$, an Empirical Case Study of Mexican Organisations." International Journal of Production Research 48 (23): 7063-7087. 2010.

[2] Ab Rahman, M.N. et al." Implementation of 5S Practices in the Manufacturing Companies: A Case Study.” American Journal of Applied Sciences. 7(8): p. 1182-1189.2010.

[3] Ananthanarayanan, K.; "Application of 5S Management System in NDE Laboratory." National Seminar on Non-Destructive Evaluation, 2006.

[4] Aberdeen Group. Lean Strategies Benchmark Report. Retrieved November 19, 2014, 2004.

[5] Altman, M. ;"An Industrial Strategy for the Clothing Sector." Industrial Strategies Project. Cape Town: UCT Press.1994.

[6] Bayo-Moriones, A.; A. Bello-Pintado; and J.M.D. de Cerio. "5S use in manufacturing plants: contextual factors and impact on operating performance." International Journal of Quality \& Reliability Management. 27(2): p. 217-230. 2010.

[7] Bell.T.; "Clothing chains wail over quotas is hypocrisy." SA Media. University of the Free State. The Star. 15 Sept.2006.

[8] Becker, J.E.; " Implementing $5 \mathrm{~S}$ to promote safety \& housekeeping." Professional Safety. 1. 46(8): p. 29-31. 2001.

[9] Cooper, D.R.; and Schindler, P. 2010. Business Research Methods. McGraw-Hill. New York.2010.

[10] Das A.; Kumar V.; \& Kumar U; " The role of leadership competencies for implementing TQM.” International Journal of Quality \& Reliability Management. 28 (2), 195-219.2010

[11] Eckhardt, B.; " The 5S housekeeping program aids production". Concrete products. 104(11): p. 56.2001

[12] Edwards, L.; and Golub, S.; 2002. "South Africa's International Cost Competitiveness and Productivity: A Sectoral Analysis". Report prepared for the South African National Treasury under a USAID/Nathan Associates SEGA Project.2002.

[13] Evans, JR.; "Total Quality - management, organization and strategy". Thomson. New York.2011

[14] Forza, C.; and Vinelli, A.; "Time compression in production and distribution within the textile-apparel chain". Integrated manufacturing systems. 11(2). 2000

[15] Glock, R.E.; and Kunz, G.I.; “Apparel manufacturing - sewn product analysis". Prentice Hall. New Jersey. 2005

[16] Gapp, R.; R. Fisher; and K. Kobayashi; "Implementing 5S within a Japanese context: an integrated management system." Management Decision, 46(4): p. 565-579.2008

[17] Hirano, H.; "5s for Operators: 5 Pillars of the Visual Workplace." Portland Productivity Press. 1996

[18] Ho, S.K.M.; "5S practice: the first step towards total quality management." Total Quality Management". 10(3): p.345-356.1999

[19] Ho, S.K.; S. Cicmil; and C.K. Fung; “ The Japanese 5-S practice and TQM training.” Training for Quality, 3(4): p. 19-24.1995

[20] Khamis, N., et al. "Development of 5S Practice Checklist for Manufacturing Industry”. 2009. 
[21] Khanna, V.K.; "5S and TQM status in Indian organizations." The TQM Journal. 21(5): p. 486-501.2009

[22] Krajewski, L.J.; Ritzman, L.P.; "Operations Management: Strategy and Analysis", 4th ed., Addison-Wesley, Reading, MA.1996

[23] MacLeod, D.; "The Ergonomics Edge: Improving safety, Quality, and Productivity." Thompson Publishing. New York.1995

[24] O'hEocha, M.; "A study of the influence of company culture, communications and employee attitudes on the use of 5Ss for environmental management at Cooke Brothers Ltd." The TQM Magazine. 12(5): p. 321-330.2000

[25] Osada, T.; "The 5S's: five keys to a total quality environment": Asian Productivity Organization Tokyo.1991.
[26] Pheng, L.S.; "Towards TQM - Integrating Japanese 5S principles with ISO 9001: 2000 requirements. The TQM Magazine.13(5): p. 334341.2001

[27] Ramdass, K.R.; 2009. "An engineering management framework for the clothing industry in SA with a focus on Kwa-Zulu Natal". Thesis, University of Johannesburg.2009.

[28] Robbins, S.P.; and Decenzo, D.A.; "Fundamentals of management Essential concepts and applications". $5^{\text {th }}$ edition. Prentice Hall. New York.2007

[29] Stevenson, W.J.; “ Operations Management”. 8th edition. Mcgraw Hill. New York.2012

[30] Ward, P.T.; Durray, R.; "Manufacturing strategy in context: environment, competitive strategy and manufacturing strategy." Journal of Operations Management, 18, 2, 123-38.2000 